\title{
Spatio-Temporal Assessment of Surface Water Quality in an Agrarian Community, SW Nigeria Using Globe Protocol
}

\author{
Akinola S. Akinwumiju ${ }^{a}$, Olawale Oluwafemi ${ }^{b}$, Ifedotun I. Abimbola ${ }^{c}$, Seyi E. Ogundeji ${ }^{\mathrm{d}}$ \\ ${ }^{a}$ Department of Remote Sensing and GIS, School of Earth \& Mineral Sciences, The Federal University of Technology, PMB 704, \\ Akure, Nigeria, 340001, asakinwumiju@futa.edu.ng \\ ${ }^{b}$ Department of Geography and Planning, University of Toledo, Toledo, United States of America. \\ Olawale.Oluwafemi@rockets.utoledo.edu \\ ${ }^{c}$ Department of Environmental Science, University of Aberdeen, Scotland, United Kingdom \\ ${ }^{d}$ Department of Environmental Science, University of Toledo, Toledo, United States of America \\ * Corresponding author
}

\begin{abstract}
This study was undertaken to assess some physical parameters ( $\mathrm{pH}$, dissolved oxygen, total dissolved solids, salinity, conductivity and oxidation-reduction potential) of stream water within the Ilara--Mokin community Ondo State, Nigeria, using standard GLOBE protocol. The data were subjected to descriptive statistics and crossplot analyses to explore the relationships among the parameters and compare the measured parameters to Nigerian and international standards. Based on these parameters, we determined the portability of stream water, evaluated and discussed the impact of these parameters on the quality of surface water of Ilara-Mokin. Parameter values were higher in the dry season compared to the wet season. Parameter concentrations correlate well with population density. Parameters' values were predominantly higher or lower than national and international standards both in dry and wet seasons. A positive association exists between TDS-salinity, TDS-EC and EC-salinity in the dry season. TDS and salinity's correlation suggests that the dissolve solids emanate from municipal wastes. The Salinity-EC relationship was strong and only held in the dry season due to high insolation and the consequent very high evaporation rate and reduced water discharge, which in turn led to increased concentration of dissolved salts in the stream water. Only TDS and Salinity exhibited positively associated in the wet season. Regardless of the season, we observed that TDS, Salinity and EC values are defiant with Nigeria and WHO standards; hence, the water is unsuitable for human consumption. Nevertheless, the studied watershed's surface water resources can meet the domestic water demand of the Ilara-Mokin community if remediated.
\end{abstract}

Keywords: GLOBE Protocol, Water quality, GIS, Nigeria

\section{Introduction}

The source of water plays a significant role in its quality. Scientifically, water quality assessment is based on the determination and comparison of some parameters with a set of standards (Jonson et al., 2020). In this case, water is said to be of low quality when the values of these parameters fall below or exceed the set thresholds (Massoud et al., 2010). Water quality assessment is of two types viz: physicochemical and biological (BisiJohnson et al. 2017). In this study, water quality assessment is based on the physicochemical properties of stream water. In this case, water quality is based on oxidation-reduction potential (ORP), temperature, color, turbidity, $\mathrm{pH}$, electric conductivity, salinity, total dissolved solids (TDS) dissolved oxygen. Oxidationreduction potential (ORP) measures a lake or river's ability to cleanse itself or break down waste products, such as contaminants and dead plants and animals. When the ORP value is high, oxygen is abundant in the water. This means that bacteria that decompose dead tissue and contaminants can work more efficiently. In general, the higher the ORP value, the healthier a lake or a river is.
However, even in healthy lakes and rivers, oxygen concentration (and hence ORP value) is lower at the bottom; because many bacteria are trying to decompose the dead remain organic matters. And as a result, they use up a larger quantity of the available oxygen. Oxygen disappears very quickly in the bottom of water bodies (often within a centimeter or two) and ORP falls quickly. ORP is measured in addition to dissolved oxygen because ORP can provide scientists with additional information on water quality and degree of pollution if present. Also, other elements can function like oxygen (in terms of chemistry) and contribute to an increase in ORP. ORP depends on dissolved oxygen in the water and the number of other elements that function similarly to oxygen. When ORP is low, dissolved oxygen is low, the toxicity of certain metals and contaminants can increase, and lots of dead and decaying material in the water cannot be cleared or decomposed.

Such organic remains laden surface water is not a healthy environment for fish or bugs. In healthy waters, ORP should read high between 300 and 500 millivolts. Total Dissolved Solids (TDS) are expected to fall below 1000 $\mathrm{mg} / \mathrm{liter}$ for healthy water, although acceptability may 
vary according to circumstances. However, water with low TDS concentrations may also be unacceptable because of its bland, insipid taste. However, the presence of high levels of TDS in water may be objectionable to consumers owing to the resulting taste and excessive scaling in water pipes, heaters, boilers, and household appliances. Water with low TDS concentrations may also be unacceptable to consumers because of its bland, insipid taste; it is often corrosive to water supply systems. The palatability of drinking water has been rated by panels of tasters concerning its TDS level as follows: excellent, less than $300 \mathrm{mg} / \mathrm{liter}$; good, between 300 and $600 \mathrm{mg} / \mathrm{liter}$; fair, between 600 and $900 \mathrm{mg} / \mathrm{liter}$; poor, between 900 and $1200 \mathrm{mg} / \mathrm{liter}$; and unacceptable, more significant than $1200 \mathrm{mg} / \mathrm{liter}$. Water with low concentrations of TDS may also be unacceptable because of its bland, insipid taste. Conductivity is water's ability to conduct an electrical current, and dissolved ions are the conductors. Salinity is a measure of the number of salts in the water. Because dissolved ions increase salinity as well as conductivity, the two measures are related. Conductivity will vary with water source: groundwater, water drained from agricultural fields, municipal wastewater, and rainfall. Salts and other substances affect the quality of water used for irrigation or drinking. They also have a critical influence on aquatic biota, and every kind of organism has a typical salinity range that it can tolerate.

Moreover, the ionic composition of the water can be critical. The proper unit for freshwater is micro-ohms $/ \mathrm{cm}$ (ohms/cm, or $\mathrm{uS}$ ); electrical conductivity dramatically depends on temperature; scientists use the term "specific conductivity" if the value has been corrected to reflect the measurement temperature. This study examined six physical parameters to determine the quality of a rural community's surface water in SW Nigeria. The main objective is to assess the surface water quality by comparing the indicator parameters with the domestic (Nigeria) and international (World Health Organization) standards. The second objective is to evaluate the seasonal variability of the indicator parameters across the studied watershed. The third objective is to examine the Spatio-temporal association among the indicator parameters.

\section{Materials and Methods}

\section{Study site}

The study area is in Ilara-Mokin; the town is located in the central part of Ifedore Local Government of Ondo State. Ilara-Mokin is about $12 \mathrm{~km}$ away from Akure, the Ondo state capital. It can be closely mapped to latitude ranging from $7^{\circ} 19^{\prime} 00^{\prime \prime}$ to $7^{\circ} 22^{\prime} 0^{\prime \prime}$ and longitude $5^{\circ} 6^{\prime}$ $0^{\prime \prime}$ to $5^{\circ} 8^{\prime} 0^{\prime \prime}$ with an average elevation of about $285 \mathrm{~m}$ above mean sea level, covering an area of $13.50 \mathrm{Km} 2$. According to her website (Ilara-Mokin.org), Ilara has a population estimate of forty-five thousand $(45,000)$ people. Ilara-Mokin is drained by a twin network of perennial streams that flow all year-round. The community is mainly inhabited by the south-western (the Yorubas) people of Nigeria, whose occupation is mainly farming.

\section{Data acquisition}

We used Hanna multi-parameter meter to determine 14 physical water parameters (see Table 1) in situ across multiple observation points along the Ilara-Mokin Community's streams, SW Nigeria using GLOBE Protocol. Before the field campaign, Garmin handheld GPS Receiver was used to establish 25 observation points. The coordinates and elevation data of the observation points were obtained. The field campaign was initially undertaken in May 2018 (after an unusual dry spell), and in October 2018 (the peak of the rainy season), we repeated the measurements across all the observation points. We designed the field investigations to acquire water quality data for Dry (May field campaign) and Wet (October field campaign) Seasons.

\section{Analytical procedure}

The logged data were unloaded from the multi-parameter meter into a spreadsheet and were cleansed. After that, we transformed the dataset to a geodatabase in the ArcGIS 10.5 environment. Inverse Distance Weighted (IDW) algorithm was employed to model single parameter thematic maps using the water quality data as inputs. We employed simple descriptive statistical techniques to explore the data and compare individual parameters with the Nigerian and World Health Organization (WHO) standards. Multiple crossplot techniques were adopted to examine the associations among the examined parameters on the $\mathrm{R}$ programming platform. We present ours results in the form of tables, graphs and figures.

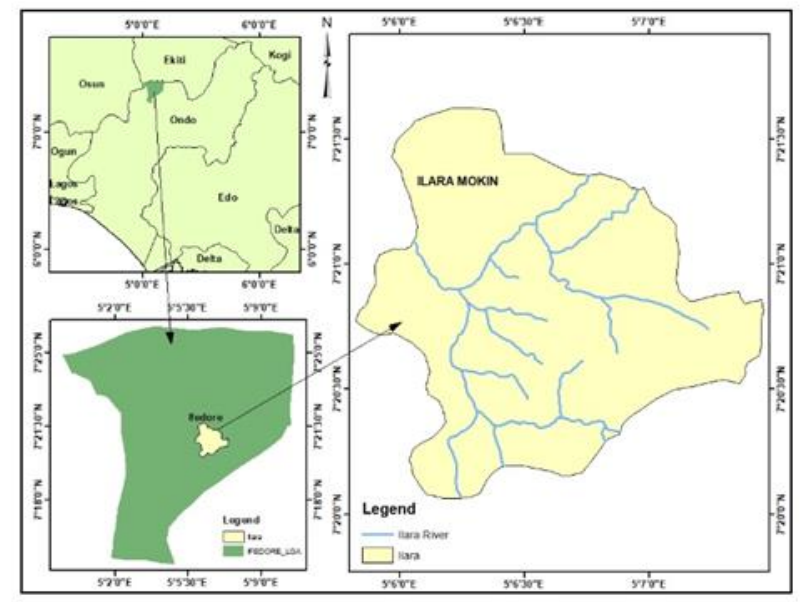

Figure 1. Figure 1. Ilara-Mokin in Nigeria. 
Table 1: Statistical summary of the water physical parameters

\begin{tabular}{|c|c|c|c|c|c|c|c|c|c|c|}
\hline \multirow[t]{2}{*}{ Parameter } & \multicolumn{2}{|c|}{ Minimum } & \multicolumn{2}{|c|}{ Maximum } & \multicolumn{2}{|c|}{ Mean } & \multicolumn{2}{|c|}{$\begin{array}{l}\text { Standard } \\
\text { Deviation }\end{array}$} & \multicolumn{2}{|c|}{$\begin{array}{l}\text { Coefficient of } \\
\text { Variance }\end{array}$} \\
\hline & May & Oct & May & Oct & May & Oct & May & Oct & May & Oct \\
\hline Temperature. $\left[{ }^{\circ} \mathrm{C}\right]$ & 25.08 & 24.86 & 28.47 & 29.03 & 26.43 & 26.95 & 1.02 & 1.37 & 25.99 & 19.72 \\
\hline $\mathrm{pH}$ & 5.86 & 6.42 & 7.01 & 7.04 & 6.80 & 6.91 & 0.29 & 0.17 & 23.49 & 41.47 \\
\hline ORP [mV] & 196.80 & -18.3 & 288 & 152.8 & 224.94 & 117.66 & 21.63 & 37.15 & 10.40 & 3.17 \\
\hline $\mathrm{EC}[\mu \mathrm{S} / \mathrm{cm}]$ & 141.00 & 115 & 392 & 271 & 302.30 & 196.20 & 68.92 & 47.54 & 4.39 & 4.13 \\
\hline TDS [mg/l] & 70.00 & 58 & 200 & 135 & 150.37 & 98.04 & 35.01 & 23.70 & 4.29 & 4.14 \\
\hline Salinity [psu] & 0.07 & 0.05 & 0.19 & 0.13 & 0.14 & 0.916 & 0.03 & 0.02 & 4.39 & 39.87 \\
\hline Pressure [mbar] & 978.6 & 979.30 & 984.5 & 985.8 & 981.85 & 982.00 & 1.52 & 1.93 & 644.27 & 508.85 \\
\hline $\mathrm{DO}[\mathrm{ppm}]$ & 0.00 & 0.00 & 1.08 & 0.98 & 0.37 & 0.20 & 0.29 & 0.34 & 1.25 & 0.59 \\
\hline
\end{tabular}

$E C=$ electrical conductivity, $O R P=$ oxidation-reduction potential, $R E S=$ resistivity, $T D S=$ total dissolved solids, $D O=$ dissolved oxygen

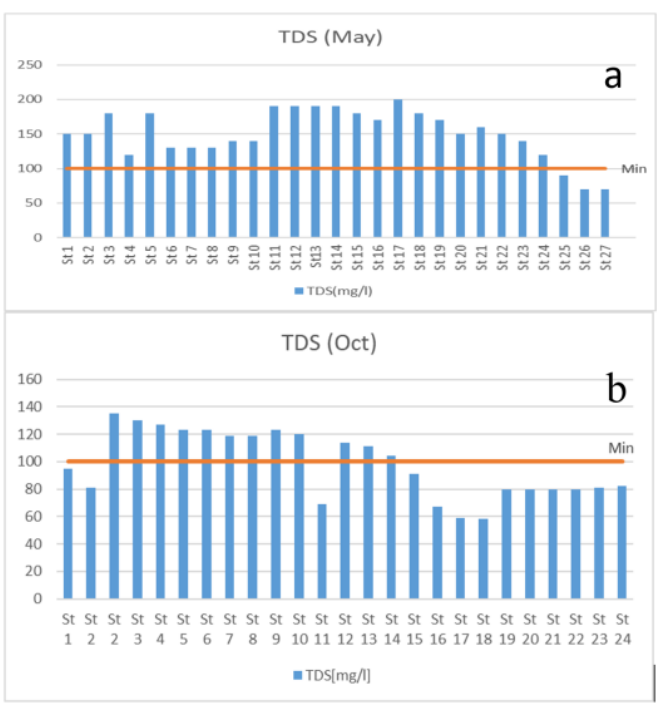

Figure 2a-b. Total dissolved solids of the stream in a) May 2018, b) October 2018.

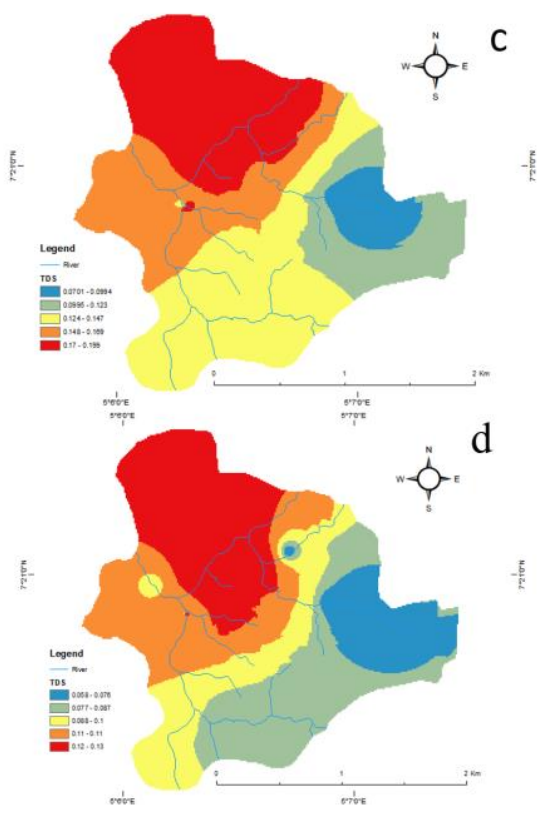

Figure 2c-d. Spatial Pattern of TDS in c) May, d) October4:48 PM.

\section{Results and Discussion}

\section{Total Dissolved Solid (TDS)}

In the month of May, we, almost all the parameters were above thresholds across all the stations (Figures 2a-b), and the average TDS value of all the sampled locations along the streams is $150 \mathrm{mg} / \mathrm{l}$. In October, TDS values were above the thresholds in some of the sampled locations (see Figures 2a-b) with an average of $98 \mathrm{mg} / \mathrm{l}$. The interpretation is that stream water pollutant concentration is higher in the dry season than in the wet season when stream discharge is high. TDS values were much lower at the upper reach of the studied watershed in the wet season. We observed that TDS values were exceptionally high at the observation points near refuse discharge points. The spatial pattern reveals that TDS values were higher at the studied watershed's lower reach in both dry and wet seasons (see Figures 2c-d).

\section{Oxidation-reduction potential $(O R P)$}

Oxidation-reduction potential values were low across all the sampled locations for both observation periods, especially in the wet season (Figures 3a-b). We observed that ORP values below the required standard (ORP values should range between 300 and 500 millivolts) across all the sampled locations. A negative ORP value was recorded for location 7 in May. Low ORP indicates a low amount of oxygen in the water. The implication is that the organic matter decomposition rate will be meager, thereby rendering the stream water unhealthy. And this will affect the lifeforms (aquatic animals and other microorganisms) of the streams, and the water will not be suitable for drinking. ORP is dependent on the level of oxygen in the water. Since dissolved oxygen is related to ORP, the stream water's dissolved oxygen is equally low, indicating that the stream water is not healthy. The spatial pattern (Figures 3c-d) of ORP shows that it decreased from downstream to the upstream in the dry season, and in the wet season, ORP increased from the downstream to the upstream. 


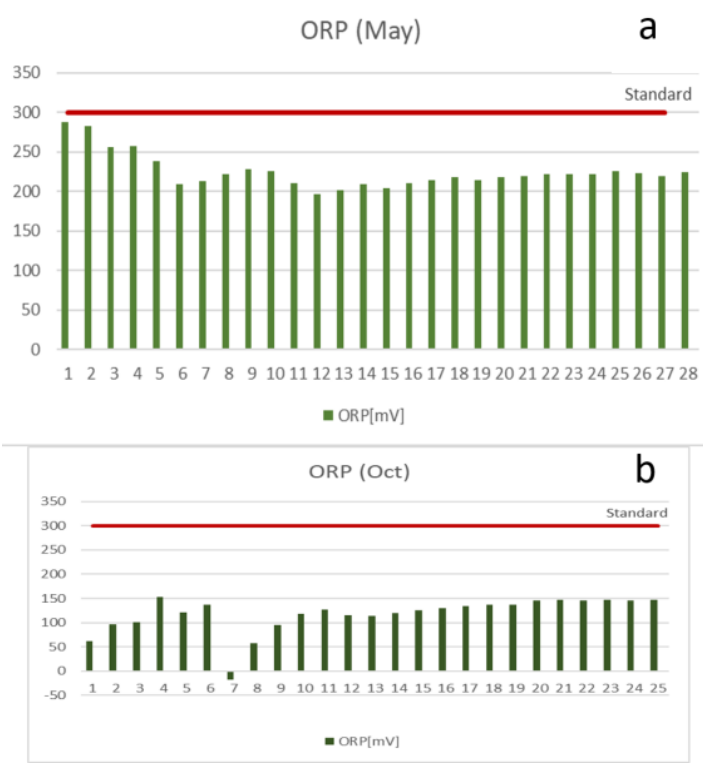

Figure 2a-b. Oxidation-reduction potential (ORP) of the stream in a) May, b) October.

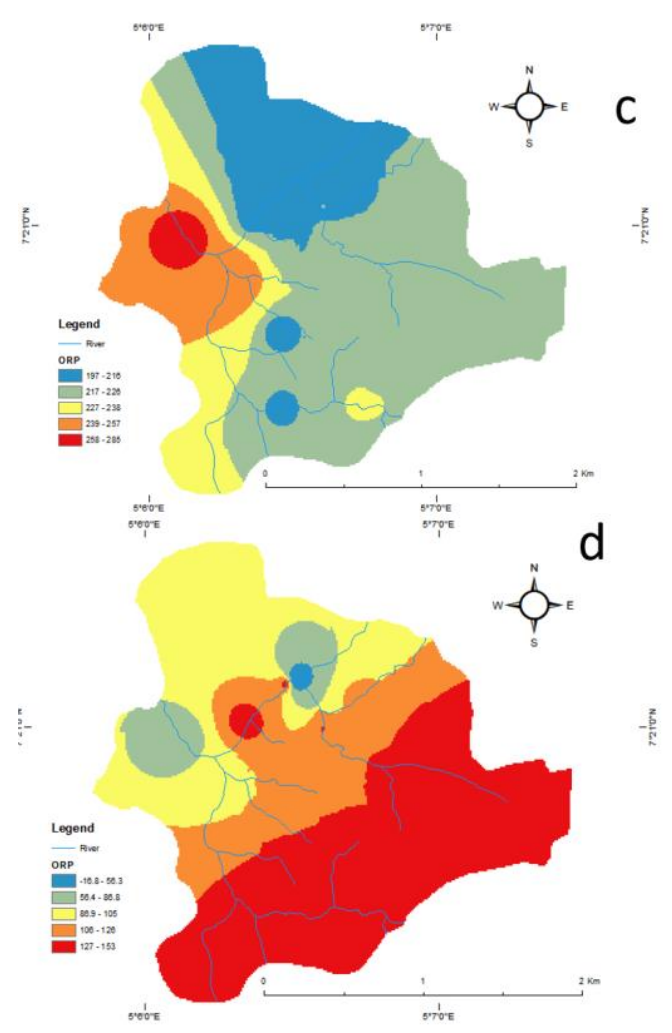

Figure 3c-d. Spatial Pattern of ORP in c) May, d) October

Dissolved oxygen (DO)

Dissolved oxygen values were generally low across the observation points. We observed that DO values were high across observation points at the watershed's upper reach in the dry season, and the reverse is the case in the wet season (see Figures $4 \mathrm{a}-\mathrm{c}$ ). The observed low values of DO suggest that the streams' ability to support aquatic life is shallow.

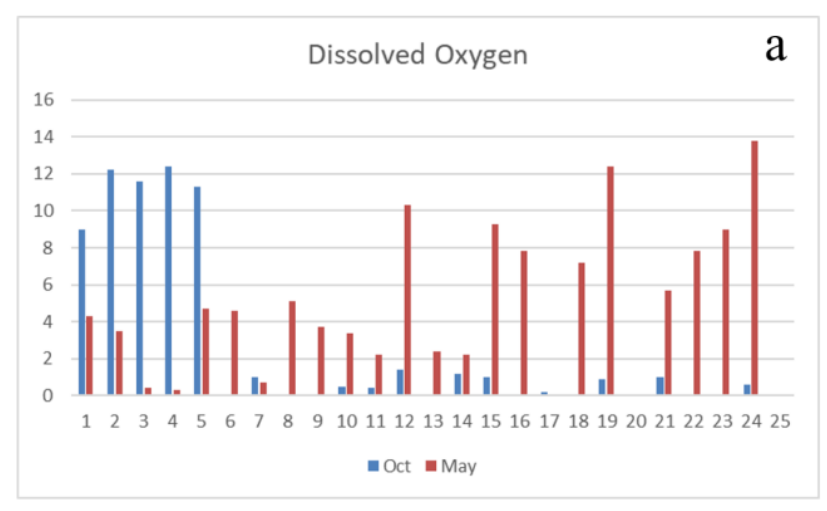

Figure 4a: Dissolved oxygen of the stream in May and October

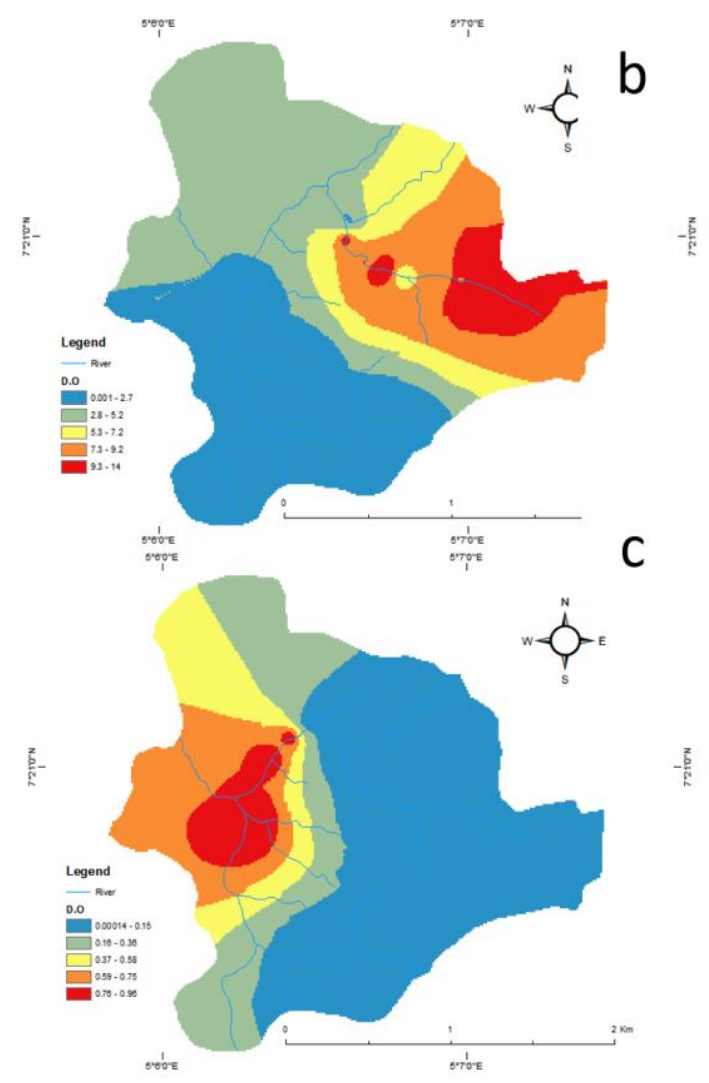

Figure 4b-c. Spatial Pattern of DO in b) May, c) October

Electrical Conductivity (EC)

Analyses show that EC values fall within the acceptable margin for almost all the sampled locations in the dry season, except for 26 and 27 (Figure 5a). On the contrary, EC values were relatively lower in the wet season (when stream discharge is at its peak and the concentration of dissolved metals is at the lowest level), with locations 12 , 17, 18 and 19 having values that fall below the lower band of acceptable EC standard (Figure 5b). We observed that EC values were higher at the lower reach of the 
studied watershed and decreased toward the upper reach both in the dry and wet seasons (see Figures 5c-d).

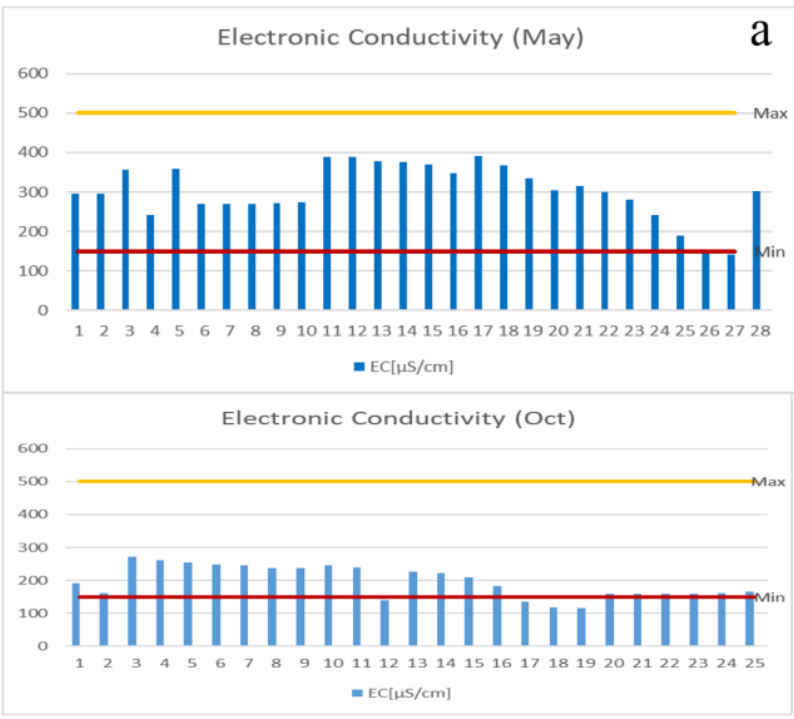

Figure 5a-b. Electrical conductivity of stream during the rainy season in a) May, b) October

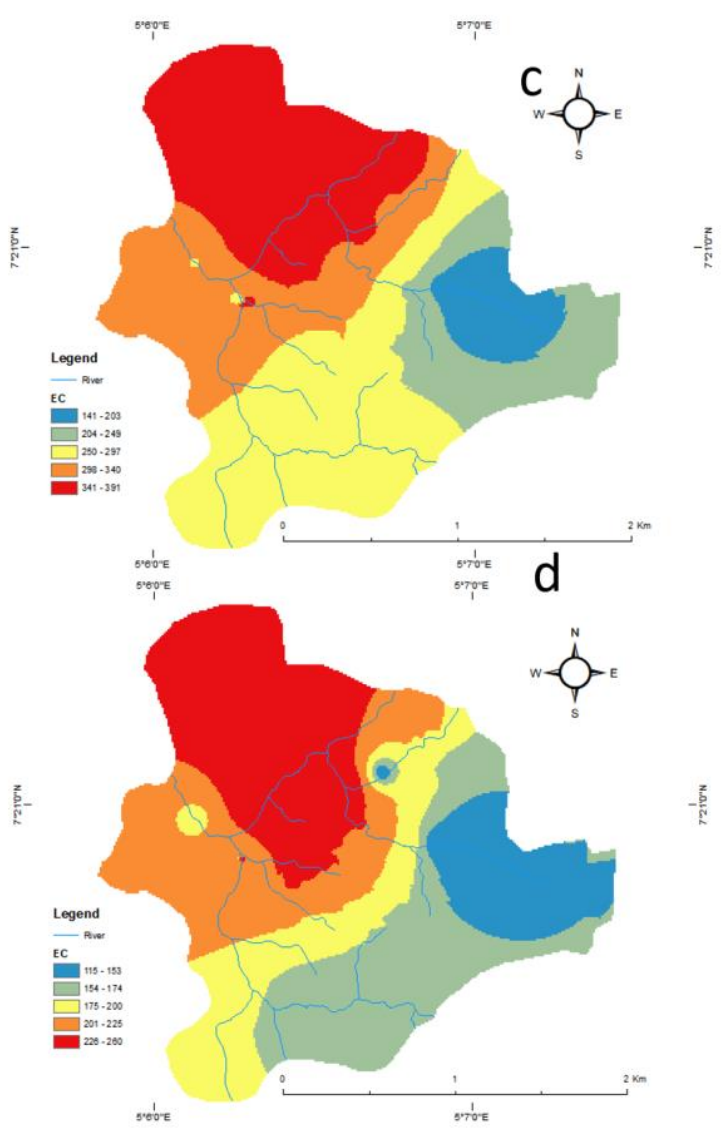

Figure 5c-d. Spatial Pattern of EC in c) May, d) October
According to the Nigerian standard, the permitted $\mathrm{pH}$ range is 6.5-8.5. We observed that the $\mathrm{pH}$ values were slightly lower across the dry season sampled locations than the wet season. $\mathrm{pH}$ values fell below the lower band of the threshold at locations 1 and 2 in the dry season (Figure 6a). PH values increased slightly across all the sampled locations (Figure 6b). However, pH values also fell below the standard at locations 2, 3 and 4. The observed acidic nature of the stream water at locations 1 , 2, 3 and 4 could be attributed to household wastes and effluents being discharged continually into the perennial streams. The $\mathrm{pH}$ range shows that crystalline basement rocks characterize the watershed's underlying lithology. The observed seasonal variability of $\mathrm{pH}$ could be attributed to household effluents and solid wastes discharged into the stream channels. The spatial pattern of $\mathrm{pH}$ (see Figure 6c-d) shows that the stream water is more acidic at the lower reach.

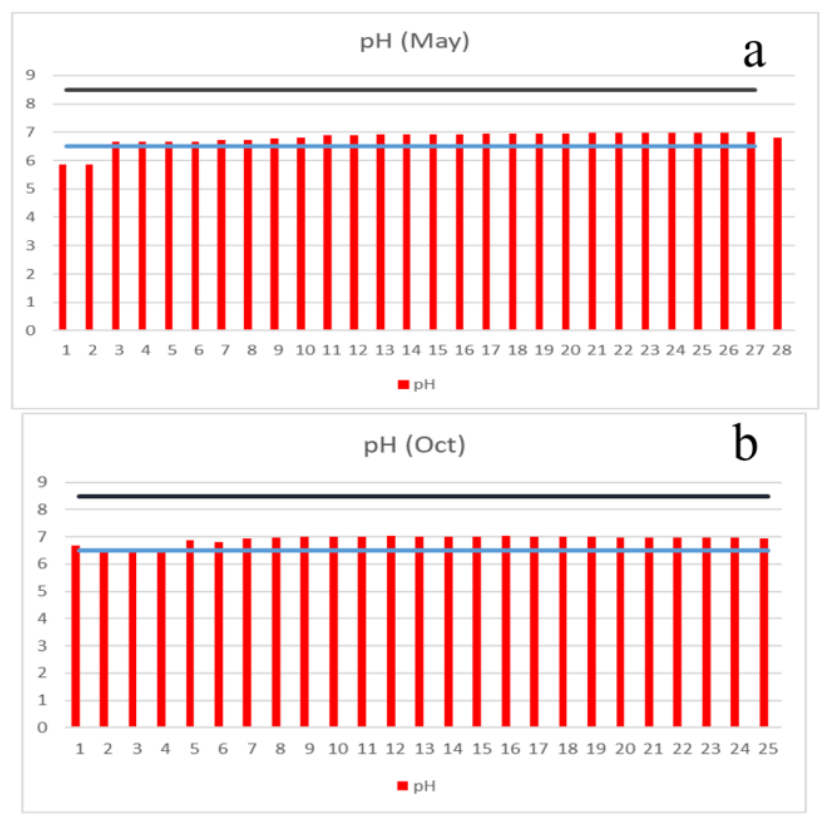

Figure 6a-b: Spatial Pattern of $\mathrm{pH}$ of the stream in a) May, b) October

$p H:$ 


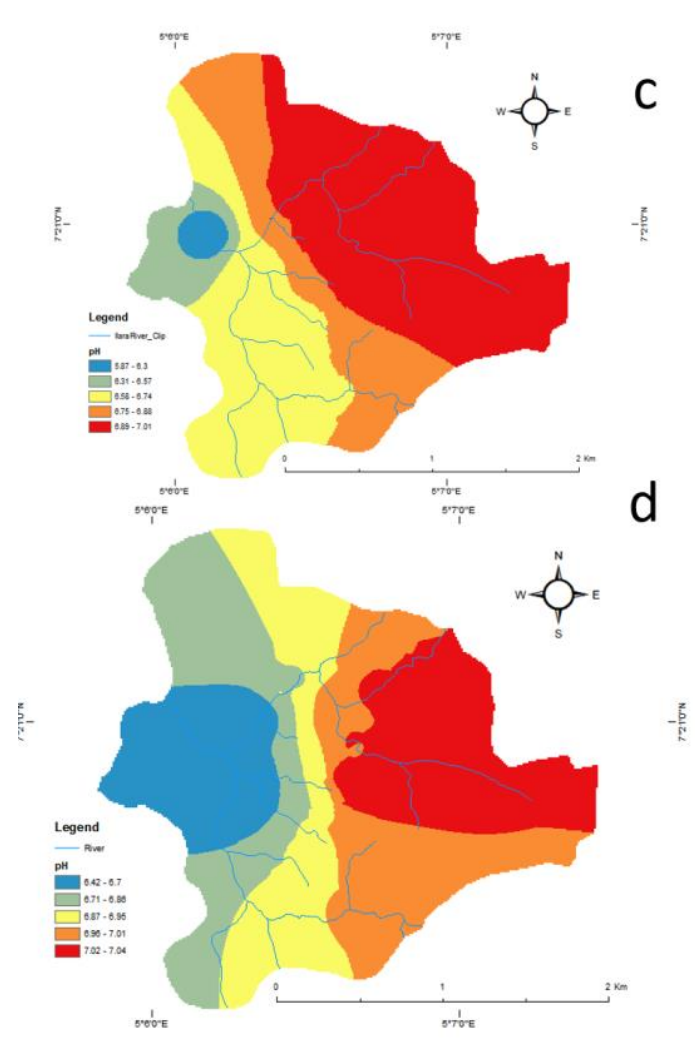

Figure 6c-d: Spatial pattern of $\mathrm{pH}$ in c) May, d) October

Temporal analysis of the relationship among selected parameters

We observed a positive association between TDSsalinity, TDS-EC, and EC-salinity (see Figure 6a). And this indicates that an increase in one variable will increase the total dissolved solids, leading to increased salinity and electrical conductivity of the stream water and viceversa. TDS and salinity's positive correlation suggests that the dissolved solids emanate from municipal wastes such as effluents from residential buildings, abattoir effluents wastes, effluents from dumpsites, and household refuse deposited into the streams daily (Habeeb et al. 2019). Similar findings have been presented elsewhere by Chen et al. (2016). Thus, the high concentration of dissolved household wastes accounts for increased salinity and electrical conductivity. Furthermore, the positive correlation between Salinity and EC suggests that as salt content or salinity of a river increases, the EC will increase; because salt influences water's electrical conductivity. We observed that the salinity-EC relationship was strong and only held in the dry season due to high insolation and the consequent very high evaporation rate and reduced water discharge, which led to increased concentration of dissolved salts in the stream water.

Contrary to the dry season results, we observed that only TDS and Salinity were positively associated in the wet season (Figure $7 \mathrm{~b}$ ). The interpretation is that salinity depends on TDS and the sources of dissolved materials.
The other relationships (TDS-EC and EC-salinity) that did not hold in the wet season could be attributed to increased stream discharge, which usually reduces salts' concentration from municipal wastes. However, we observed that TDS, Salinity and EC values deviated from Nigeria and WHO standards.

Consequently, the surface water of the Ilara-Mokin is unsuitable for human consumption. Unlike most studies (such as Johnson et al. 2020; Bisi-Johnson et al. 2017; Chen et al. 2016) on surface water quality, we utilized primary data measured in situ. Hence, our findings are based on datasets that are characterized by high accuracy. Finally, this study's uniqueness hinges on adopting the GLOBE Protocol, which permits direct comparison with findings in other parts of the world where similar data collection procedures are implemented.
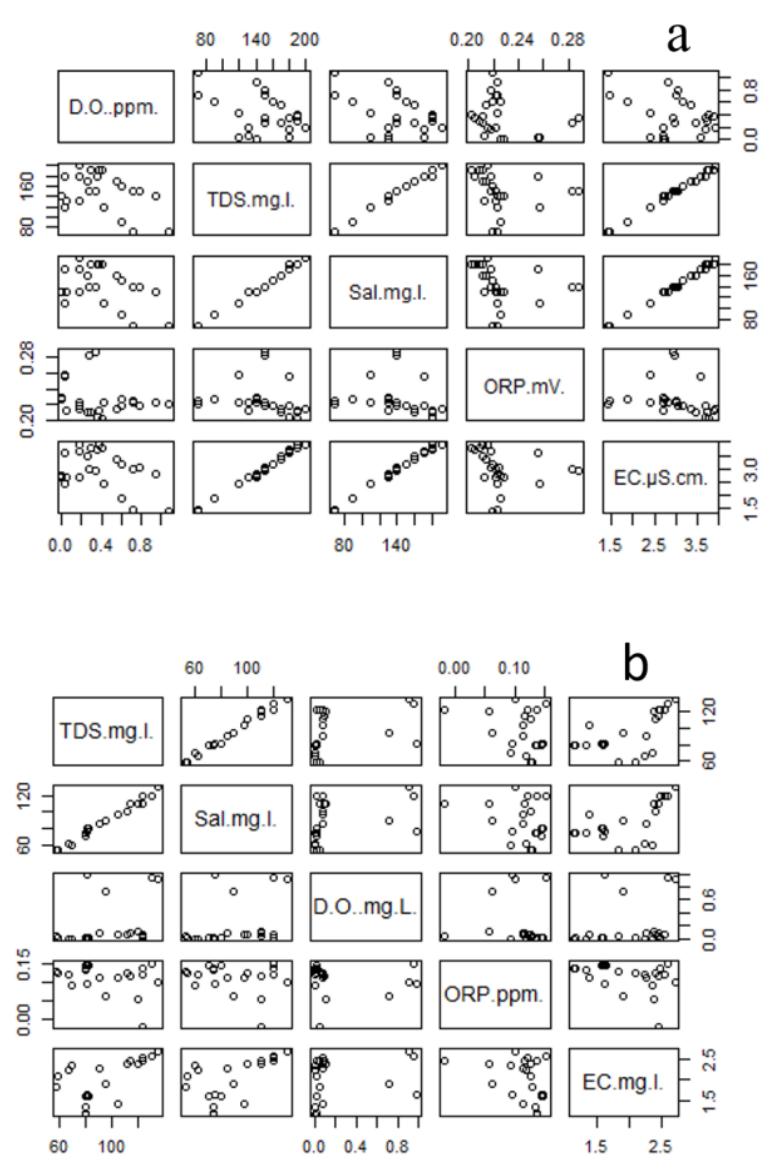

Figure 7a-b. Crossplot of selected parameters for (a) dry season and (b) wet season

\section{Conclusions}

This study attempted to assess a rural community's surface water quality in SW Nigeria using GLOBE protocols. Data on ten physical water parameters were collected across multiple observation points and a network of perennial streams in the dry and wet seasons. We subjected the water quality data to statistical analyses to explore the relationships among the parameters and compare the parameter values with national and 
international standards. We draw the following conclusions from this study: Temporal variability of the examined parameters is seasonal. Parameter values are higher in the dry season compared to the wet season. The spatial pattern of the examined indicator parameters correlates well with population density. Parameter values are predominantly higher or lower than national and international standards. The surface water of the studied watershed is generally polluted and has been rendered deleterious. The stream water pollutants emanate from municipal wastes such as household effluents, solid waste, and agricultural waste. Remediation of the surface water of the studied watershed is possible. The watershed is endowed with abundant water resources to meet the community's domestic water demand if remediated

\section{Acknowledgment}

We acknowledge YLACES, USA, for providing the equipment used in this study. Our appreciation equally goes to the inhabitants of Ilara-Mokin for their cooperation and assistance during the field investigation.

\section{References}

Johnson O. O., Aboyeji, O.S., Akinwumiju, A.S. and Adelodun, A.A. (2020). Fuzzy Logic Interference for Characterization of Surface Water Potability in Ikare Rural Community, Nigeria. Journal of Geovisualization and Spatial Analysis, 4:1. Doi:10.1007/s41651-0190044-z

Chen Q, Mei K, Dahlgren RA, Wang T, Gong J, Zhang M (2016) Impact of land use and population on seasonal surface water quality using a modified geographically weighted regression. Science of Total Environment, 572:450-466

Habeeb R, Gupta Y, Chinwan H, Barker E (2019) Assessing Demographic and Water Sensitivities Arising due to Urban Water Insecurity in Haldwani, Uttarakhand (India): a GIS-Based Spatial Analysis. Journal of Geovisualization and Spatial Analysis, 3:8

Bisi-Johnson M, Adediran K, Akinola S, Popoola E, Okoh A (2017) Comparative physicochemical and microbiological qualities of source and stored household waters in some selected communities in Southwestern Nigeria. Sustainability 9:454

Massoud, M. A.; Abdolmonim, A. A.; Jurdi, M. and Nuwayhid, I. (2010). The Challenges of Sustainable Access to Safe Drinking Water in Rural Areas of Developing Countries: Case of Zawtar El-charkieh, Southern Lebanon. Journal of Environmental Health, 72, 24-30

Nigerian Industrial Standard 2007. Nigerian Standard for Drinking Water Quality, ICS 13.060.20. [Online]. Available: https://africacheck.org/wpcontent/uploads/2018/06/Nigerian-Standard-forDrinking-Water-Quality-NIS-554-2015.pdf

Oxidation-Reduction Potential (ORP). [Online]. Available: https://www.enr.gov.nt.ca/sites/enr/files/oxidationreduction_potential.pdf

World Health Organization. Total Dissolved Solids in Drinking Water: Background document for development of WHO Guidelines for Drinking-water Quality. [Online]. Available: https://www.who.int/water_sanitation_health/dwq/chem icals/tds.pdf 